\title{
Evolution of the Language of Art: Cultural and Artistic Influences
}

\author{
Oleg Krivtsun \\ Department of Sociology of Art \\ State Institute for Art Studies \\ Moscow, Russia. \\ E-mail: Oleg_Krivtsun@mail.ru
}

\begin{abstract}
The factors of the evolution of the language of art are considered. Mechanisms of coexistence in modern culture of art classics and non-classical. Culturally dependent properties are revealed in the evolution of art, the main subject of which is the person of the epoch, the boundaries of his cognition, and the modification of historical mentality. According to the author, there is no "timeless" canon of correct artistic vision, it changes together with a complex set of cultural and artistic stimuli. A great role in the evolution of art is played by the mechanism of self-movement of artistic languages. In unknown forms, the artist is looking for something that is not in the known. The presence in the product of great ideas is not a guarantee of his artistic quality. The principle of the self-worth of art is still significant for modern culture, art is not only perceived, it is loved. The artistic experience extinguishes all functional and practical orientation.
\end{abstract}

Keywords-languages of art; culture; evolution; historical mentality; creativity; self-movement of art; self-worth of art

\section{INTRODUCTION}

Classical art occupies strong positions in the modern world. They are admired on all continents. The multimilliondollar statistics of visiting large collections of masterpieces from museums in Europe and the US are impressive. In this connection, one often hears a question from an uninitiated person: why does the language of art continue to be modified? So many difficult centuries have passed, while the language of painting, architecture, sculpture reached its apogee, accumulated and reworked all previous artistic experiences and accumulations, gained unprecedented discoveries. During the 16th -18 th centuries, such fine works were born in European art, which rightfully we call classics, classical ways of transforming the faces of the world and man. We see how such classicists as Leonardo da Vinci, Michelangelo, Raphael, Rembrandt, Vermeer, Velasquez, Rubens, Giulio Romano, Lorenzo Bernini took place in the fullness of their designs - and these are remarkable events, art-exquisite! Today, future artists in special educational institutions of Russia are also taught academic mastery, an opportunity to master practically all the wisdoms of classical pictorial writing: the skills of classical color-light and spatial composition, the classical perspective, the stable arrangement of volumes inside the canvas, the formation of the center of gravity of the picture, the sfumato technique, and much more.

However, only a few graduates of art institutes are able to creatively translate modern life into a purely classical language of painting. More appreciated is the individual style, author's recognizable writing techniques, attention to one's own world view embodied in the picture. And there are many explanations for this. Already almost one and a half centuries in the fine arts, as well as in other types of art, the so-called "non-classicism" dominates. Beautiful, since the second half of the XIX century, still can be a theme of art, but no longer serves as its end in itself. In terms of such criteria as artistic expressive, interesting, entertaining, original. For more than a century and a half, the so-called nonclassical art fills the artistic life of contemporaries, beginning with the Impressionists (especially attractive today, and in life - very suspicious for critics).

We also enjoy outstanding works of expressionism, completely nonclassical, but surprisingly modern, sharp, "scratching" us, however, giving life to a multitude of modified currents of pictorial writing for over a hundred years. Examples can continue: in the domestic art, the classical canons exploded Natalia Goncharova, IlyaMashkov, Robert Falk, as well as the Jack of Diamonds in general [1]. Later-KuzmaPetrov-Vodkin, PavelFilonov, Alexander Deineka, Alexander Labas and many others.

\section{History OF THE LANGUAGE OF ART AS A PERSON'S HISTORY}

Here it is appropriate to recall Goethe: in an interview with Eckermann he said that the whole history of world art can be reduced to 36 plots. Human life is not so rich in events - childhood, the conflict of children and parents, the man and his love, man and betrayal, man and death. [2]. But every new artist "one and the same life" is being transformed in a new way, only in his own way, through special stylistic devices of the language. Thus, each new author finds in his works new meanings, unexpected accents, new colors of the world picture.

That is, in art, the old subjects (the birth and death of a person, the conflict between children and parents, the conflict of generations, the man and his love, the person and 
loneliness, the individual existence of the person VS opposing the society, etc.) continue to live in art, but they acquire a new content, a new artistic interpretation. Attention remains to the designated constants of human Being and, at the same time, are completely innovative ways of their creative implementation.

One of the greatest mysteries of art is in his ability to present this limitation of subjects through an unlimited variety of artistic forms, achieving an unstoppable artistic renewal of "one and the same life".

Therefore, in the history of art, it is more important not "what", but "how". It is because of the dissimilarity of the ways of stylistic and linguistic realization of human life in different epochs, the continuous modification of the methods of artistic expression in culture, that we are able to recreate the history of man himself in these changing forms.

Read on the history of an individual (the individual world of a particular artist) the corresponding fragment of the history of mankind as a kind. That is, it is productive to connect ontogeny and phylogeny. Hence the historically developing form of any work of art is evidence not only of the skill and artistic traditions of the epoch, but also the source of our new knowledge about man: how the ways of his perception and sensuality changed, how he saw or wanted to see himself, how he developed his dialogue with the inner world, moved a selective interest in the environment, etc. The evolution of artistic forms, taken on a world scale, traces the grandiose trajectory of the movement of the human spirit.

It turns out that the history of art is a person's story? This and so and not quite so. The evolution of the language of art is influenced in different ways by both cultural and artistic factors. Cultural - this is the concentrate of the intellectual life of the era, the artistic picture of the world (in many respects born of the artist irrationally), the influence of the dominants of the mentality of the environment close to the artist ("own" and "alien" groups) and much more.

Artistic incentives for the development of the language of art - is the desire to overcome the harsh ways of expression, established formulas in any art form. That is, to resist the process of "aesthetic wear of the form", which always leads art to stagnation. All this is discussed below.

A great contribution to the interpretation of the anthropic, humanoid nature of art was made in the 20th century by the French School of the Annals (École des Annales). In the brilliant works of Mark Bloch, Lucien Fevre, Le Goff, FernandBraudel, and other enthusiasts of the "New Historical Science" (La Nouvelle Histoire), the great history of mankind was interpreted precisely as History, and not as a combination of different, unlike epochs. Acquaintance with the new methodology - studying history as a continuous history of ideas, as a history of mentalities, changing the types of the basic person of the age, had a positive impact on the new methodology of art history. Today we can conclude that the techniques of artistic expressiveness are transhistorical, they make their way through the junctions of different eras and cultures. Artistic forms did not exist by themselves. Outside these forms, a person would be tongeless and wordless. Along with the evolution of the language of art, the person himself developed, his emotional and intellectual sphere. Together with the development of man, a new impetus and development of artistic forms were obtained.

The history of artistic representations of different epochs is not limited to what one or another art historian, aesthetist, philosopher said about art. The artistic consciousness of the era absorbs all the existing reflections in it about art. Its structure includes the existing ideas about the nature of art and its language, artistic tastes, artistic needs and artistic ideals, aesthetic concepts of art, artistic assessments and criteria of artistic quality, formed by artistic criteria, etc. All this multifacetedness of the artistic consciousness and its historical mobility must be uncovered by relying on the analysis and generalization of real facts, that is, on the basis of the study of contemporary works of art of the epoch, as well as its imperceptible, sometimes marginal works, from which then often new dominants art.

This is extremely important, because the artistic consciousness of the epoch expresses not only artistic theories. The creative practice of all kinds of arts, the cultivated mass forms of artistic leisure, etc., participate in the composition of the artistic consciousness of each historical stage. The study of the laws of the evolution of the history of artistic consciousness in such a volume will accumulate its real content, and not be reduced to the history of artistic culture as to the "tadpole story".

However, if there was no historical science, and only the history of the arts existed, we could, from the history of creative practices, recreate the history of man. There are such tectonic shifts in the history of painting, the history of sculpture, the history of architecture, which are very informative for understanding new mental and emotional orientations that have flared in the culture, for understanding historical mentality, its dominants.

Thus, the well-known transition in the history of fine art of the composite composition of the painting from classical symmetry ("pyramid") of the Renaissance to the diagonal composition at the end of the 16 th $\sim$ early 17 th century was not arbitrary. He marked the legitimacy of the appearance of a point of view on a pictorial canvas, a departure from the impersonality of the Middle Ages. This fact itself testified of a new shift in the attitude of the world, of consciously emphasizing that the picture is the result of the subjective perception of the viewer that the artist, like the viewer, can freely change the point of view and is not obliged to stop at all against the central axis of action.

Here it is important to emphasize the thesis: a man of the XVII century looks at a new canvas for him, overcoming the old traditional stereotypes of writing. He is surprised by his unusual compositional structure, the author's plastic thinking, the compositional solution, which is sometimes completely formed by color and light spots (for example, such an unusual, explosive for his era, and now Rembrandt's soloved Night Watch, 1642). The viewer tries on himself the coordinate system set by the artist, that is, comprehends, gets 
used to the "new artistic optics", the new techniques of the pictorial language, and even begins to get pleasure from it.

In this connection, one can make such a generalization: by assimilating the ways of dealing with various creations, with the new laws of their organization, any person learns to grasp new types of integrity, unite the previously uncompound in his mind, master new methods of artistic thinking, and "appropriate" them. Psychologists have established such a regularity: the viewing of a complex pictorial picture, of an unfamiliar composition space trains the Gestalt's abilities — that is, grasping initially seemingly dissimilar elements as combining, as being reconciled in a new way, that is, as a single whole created according to new artistic principles.

The same is true of music - when our perception follows the complex transformations of the melody, behind opposing voices, counterpoint, then the listener's thinking passes all those vicissitudes and metamorphoses that passed the thinking of the composer, the artist. He is mastering the new intonational system, new models of musical thinking, such as, for example, the sonata form, from which the shape of the symphony also grew later.

As you know, the sonata form crystallized into a stable structure in the second half of the 18th century, reached its climax in the works of Haydn, Mozart, and, in particular, Beethoven. The difference of the sonata form from all others lies in the fact that the developing section (development) is central in its meaning, it shows the main reception of the dramaturgy of the sonata form - conflict and dynamics of development. In no other former musical form did development have a decisive, "ideological" meaning. The sonata form made it possible to combine the most diverse material, sometimes in a very large time space. Of course, all of these innovations in music have also affected the sophistication of contemporaries' thinking. And, at the same time, they gave the person the opportunity to live and master such a conflict dynamic development and ways of solving it, which carried out various mental models of his own human Being. The interaction of mental and cultural influences and a new vision of the artist himself taught to comprehend a person's dramatic life, new, more complex patterns of conflict, to grasp a large temporary whole as a special dramaturgic UNITY, to come to a new experience of catharsis.

Thus, the originality of the artistic language at any stage of history trains the ability of the person's imagination. His associative apparatus trains, helps a person break down the formulas of everyday thinking, helps him to be included in modern ways of comprehending the world that are not easy for him.

Similarly, in the baroque: the dynamism, spontaneity of the movement of baroque forms, their excessiveness, redundancy, often deep mysticism - all this, it would seem, according to Winckelmann - "piling up the wrong". But inside the Baroque, undoubtedly, there is a rule, its excessive, elemental and redundant dynamics we perceive as a kind of model of the world picture. And such a picture of the world, which does not embody a pure "transition", but can exist for centuries. In Baroque works, its element and attraction. First of all, it concerns an outstanding Italian sculptor and architect Lorenzo Bernini (Giovanni Lorenzo Bernini). Today, we highly appreciate the catchy flamboyance and dynamism of forms in the paintings of Pieter Paul Rubens, and, of course, by Caravaggio (Michelangelo Merisi da Caravaggio). Now there is no doubt that, wanting to enjoy the creativity of artists of different styles and eras, we must be able to correctly adjust the register of their vision. Each of us should have a "tuning fork in the eye", which is able to absorb aesthetics (the quality of artistic expressiveness) of various artists. To be able to appreciate the artistic quality of works of different epochs of different styles.

\section{RELATIVITY OF ANY HistORICAL ARTISTIC STANDARD}

Thus, at first in the Renaissance coordinate system, the senses of measure, harmony, symmetry were conceived as beginning absolute for the addition of a work. But in subsequent epochs there are practices that demonstrate the relativity of the norm, the special expressiveness of the "wrong" in art (Baroque, Romanticism, Impressionism, Expressionism). At first, antiquity served as an indisputable starting point, which set the "spin-off" for all artistic forms. Thus, Winckelmann in his art history built the movement in this way: from the right (antiquity), grew up incorrect (the Middle Ages with its distorted forms and proportions). And then the correct one was born again from this wrong (Renaissance). After the Renaissance, baroque (again incorrect) follows, competing and provoking the correctness of classicism, etc. [3]. Winckelmann noted one of the principles: the history of art often moves on the principle of negating negation, one artistic era arises as a negation of the other.

Such a principle of movement in contrast was repeatedly considered as a universal mechanism in the twentieth century. Representatives of the German school of art history can find ideas on the general history of art as an alternation of the principles of classicism and romanticism, accumulating the main tendencies of creativity. Obviously, in the violations of the norm, in the creative deformations of visual-real, there is a great deal of meaning. The artist is experimenting, trying to connect the incompatible, slightly deforms nature, and suddenly such a combination suddenly pops up, such an unexpected plastic find that notifies the author of its significance, nonrandomness. With all plastic epatage and "jokes" in the history of painting, there remains not an experiment in itself, but those plastic solutions that contain something essential, significant. Through an unfamiliar expression so far, from time to time new ways of organizing the "force field" of the picture are being shown, not yet understood by everyone.

I'll give you a small, but typical example. As you know, Picasso was an excellent draftsman. In 1906 he wanted to create a portrait of Gertrude Stein - his like-minded friend, producer. According to Picasso, this should be a portrait in the highest sense of the word. The artist spent about 80 sessions (such a number for him, it was not typical!). Then he destroyed all the sketches and later created a portrait from 
memory in the spirit of protocubism. On the question of his friends -"Does he really think that the portrait is similar to the model?", The artist replied: "Now, maybe not. But one day it will look like". This paradoxical answer is fraught with a deep truth: a great artist is always convinced that he sees beyond his contemporaries, he feels thinner. And that over time, the laws of collective perception will evolve exactly in the direction in which his creator already feels.

Therefore, what we are accustomed to evaluate as the search for new methods of expression - the combination of different methods of writing in one picture, the principles of bricolage, the principles of connecting images and allegories of different epochs - reflects important real changes in the laws of human perception. The product lives if it captures the acupuncture points of human existence, responds to them. To put it differently - it fully expresses the mental dominants, regulates the difficultly perceived intellectual and sociopsychological "chaos" of its time, most fully expresses the spirit of its era.

Modern art is blamed for the fact that it seems to be able to act both "against man" and multiply social fears with its sharply negative image. This is a difficult question. Here, the criteria for the artistry of art are raised. Undoubtedly, the newest trends in art should not disable the human psyche. What then is the answer to the question about the diagnosis of the artistic quality of art?

From foreign colleagues, I have heard such opinions many times: Francis Bacon is terrible, catastrophic, but for some reason his work wants to be reviewed again and again. Is this one of the criteria for the authenticity of the work the hypnotic desire to return to it again? Painter Bacon sends a sharp message to mankind, blows up the man himself, fixes in life the aspects of destruction and self-destruction, the apocalypse. However, if the artist brings his hand over the canvas and transforms the wounds of individual and social Being- it means that the artist himself is able to diagnose himself. And this is not so little. That is, the creator does not drop his hands - he writes pictures and, like us and himself, obviously thinks he owns the situation, he realizes himself if he does not own the situation, he is a participant in what is happening. I think that this statement is also true for understanding similar trends in modern music, in theater, in literature. The artistic experience of such works by the spectator evokes complex forms of catharsis. This phenomenon has yet to be carefully examine.

In this connection, I would also affirm such an additional criterion of authenticity: on the one hand, full-blooded artistic expressiveness, and on the other hand, the vitality or vital force of a work is one and the same. These concepts today are identical and in many ways help us to find the criteria of artistic quality. If a complex and sharp-dramatic work is before a person, and he sees in him not only a passionate statement, but also a passionate denial - strangely enough, but the vital forces at this moment are strengthened. That is, the experience of the vitality of the work, if any, can be regarded as the most important identification property of the newest artistic creations that have parted with the traditional categories of measure, harmony, and even catharsis.

Such a criterion - the experience of a sense of vitality in the perception of a work - can help a person to appreciate the significance of the incomprehensible language of the work, to separate the grains from the chaff, which is why so diverse a new world art process guides us, alas, not devoid of artistic profanity. The concept of the vitality of the work needs in special studies that we wanted and are going to take in the foreseeable future.

The poet Guillaume Apollinaire, analyzing the methods of complicated writing in contemporary painting and poetry, remarked: "The contemporary poet holds in one line what the former one has spread over four stanzas". The same and in painting. That is, it is another cultural and artistic factor in the evolution of the language of art. The point is that the level of complexity, fast associativity of our consciousness is so denser with time that the artist is better and more creative "not to finish" than to be overly verbose in his means.

In this connection, we are talking about such contemporary art phenomena as "open form", as simultaneity, as synergetics of the finished work - these are also important measurements by artistic means of what is accomplished in real human memory, in the psyche, in consciousness, in cultural anthropology. The density of the associative apparatus of modern man is such that only one hint, one pictorial phrase - instantly recreates the WHOLE. The newest person does not need such detailed exposition as in previous centuries, since his actual artistic memory, his inner vocabulary of symbols exist in constant flow, and interaction, mutual enrichment [4].

Let us once again consider the question of the artistic factors that influence the evolution of the language of art.

Take a picturesque picture or graphics. Let's look at the work. And we will see that, on the one hand, we have a complete, complete work, but at the same time - the artist draws as if by two sides of the line. I mean such artifacts as "external" and "internal" that have been forgotten by art historians.

First, there is a line in the work that is directly addressed to the emotional-sensory perception (external form). We are looking at a new picture and there is a kind of "emotional blow". Perception of colors, their combinations, pattern, composition, arrangement of volumes, harmonious structure or underlined dramaticism of the picture can plunge us into melancholy, or cause emotional excitement or make you think hard. Or give unconscious pleasure, comfort. Or to arouse the premonition of the conflict with the accompanying anxiety.

All this - the spectra of emotional reactions to our primary perception of plastics. The first signal system responds first to the influence of the external form of the picture.

But we know that at the same time the artist symbolizes something with this line, there are hidden subtexts, 
mediations, pictorial metaphors, picturesque allusions, that is, besides a purely emotional hypnosis tells us about a person, about himself, conveys the subtext of the picture. From within, the theme, the idea of the work, its meaning can grow. But the theme is an integral living space, not with one but with a multitude of voices. Interpretation of the topic may be a step towards our inner worldview, or it may not be, encountering the resistance of our thinking, our experience. In any case, the anthropic interpretation of "pure plastics" connects the second signal system (internal form) to the first signaling system. We compare, joyfully amaze, exult, enjoy, let in, or we estimate the picture coldly, we wait for comments, we select that register, that coordinate system, which is able to really open for us a yet not completely understandable plastic space.

Consequently, the same line in art - at the same time there is both sensory-penetrating and conceptual.

Thus, in the process of creating a work, any artist faces the solution of a two-pronged problem: the deployment of plastic thinking, on the one hand, is subject to artistic techniques. On the other hand, in a genuinely innovative work, there should always be not only technical virtuosity, but also an important ontological component, that is, the sounding of the hidden, not explicit, essential aspects of being. This is a state where "the perception of a work" makes one think a lot, moreover, while no concept is adequate to it'(Kant). In other words, in a large work, there is always a direct discretion of the truth, not based on evidence.

Thus, I bring to mind another factor of artistic evolution: there is such a thing as the mechanisms of self-movement of art. This means that the impulses of artistic creation can come not only from the surrounding world, but also dictated by such motives as artistic taste, the demand for picturesque expressiveness, the desire to bring down the usual artistic attitudes, to break the deception of expectations. Innovative artistic techniques appear as a creative aesthetic move, as a fundamentally different system of coordinates, or as a kind of alogism, but very attractive, creative, forming quite different methods of perception.

Many of the drawings of Claude Monet, Paul Cezanne, Georges Braque, Maurice Vlaminck, IlyaMashkov, PyotrKonchalovsky, Pavel Filonov have a remarkable quality: this is a feeling of organic growth of the form, which is built from within, as it were, groping for its limits. And the boundaries of the form may not be indicated, but only guessed.

Thus, it can be concluded that art is valuable to us, and OUTSIDE its plot. And simply as an object of immanent development, the result of maestry, when the painter "scoops by brush" reaching the apotheosis of pictorial and plastic perfection!

The artist begins to write an etude - and suddenly you get a magnificent picturesque still life or landscape. Experts say the existence in any work of "epicenters of activity", which can be interpreted as certain plastic dominants of the picture, sculpture, architectural work. Such "epicenters of activity" can be found in and in terms of the composition of the work, and in its imagery, color, contrasts of light and darkness. "Epicenters of activity" form an artistic drama, they lie at its base. Well written about the expression of plastic drama Sergey Daniel: "Cut down, carved into contrasting planes, with the active use of light and shade, these forms produce the effect of "disturbance" of the spatial environment. If the image includes a whole series of forms intersecting "orbits", the picture turns out to be extremely complex, revealing the hierarchy of the centers of "perturbation", spheres of their influence, etc."[5]

When we want to particularly praise the skill of the artist, we say that "in this work every point of the picture knows about the existence of all others", that is, we note the organic dependence of the links of the whole work. Emil Bernard said that Cezanne completely rewrote the picture after he put on the canvas a few amplifying sounds of smears. Otherwise: small transformations dragged along all the previous colorful pigments. This is another confirmation that there is nothing minor in the picture that has taken place: a fragment, a corner or an insignificant detail. Everything should be felt at its only possible place. It is in this expressiveness - the classic understanding of the integrity of the work.

Summarizing what has been said, it is important to note that the analyst of artistic form encourages us to speak of "two truths" - an extra-artistic, cultural (coordinate system in which nature, object, exist outside of art) and actually artistic or architectonic. Consequently, we can conclude that the architectonic truth grows through the artist's vision, through his individual sense of tectonics, spatiality, texture, linearity. True, today such a point of view is increasingly expressed: in connection with the growing freedom from the stable artistic rules, tectonics in art recede into the background, while the first in the work of art is the individuality of the master, human existence. This, in particular, can be seen from the latest works of architecture, from works of sculpture and painting.

\section{CONCLUSION}

In conclusion, I note: the nature of art cannot be reduced to the totality of its various functions. Because contributing to knowledge, art does not dissolve in science, contributing to the education of morals - does not replace ethics and so on. Therefore, art is an original form of spiritual creativity, having a goal in itself. To art, a person turns, wanting to enjoy, to experience catharsis, satisfaction, in the work of art the moment of admiration, sensual experience is always strong. What is capable of giving man art, can not be found in any other form of spiritual creativity.

From the "substance of life" - fragmented, eclectic, loskutnogo - the artist creates a "substance form". Reflecting on the mystery of this transformation, aesthetics developed ideas about special mechanisms - entelechy, artistic metabolism, etc. The peculiarity of the artistic form is that the meaning embedded in it turns out to be untranslatable in the language of concepts, inexpressible until the end by any other means. This is confirmed by the idea of the self-worth of art. Art is not only perceived, it is loved. The artistic experience extinguishes all functional and 
practical orientation. The paradox is that art is able to satisfy the artistic need only if it does not act as a means, but as a goal. Only discovering its originally self-valuable nature, which is not replaced by any other moral, religious or scientific activity, art is an excuse for itself, asserting the necessity of its place in a person's life.

The idea of the self-worth of art is extremely difficult to break through to itself in history. Each artistic era did not leave behind an unshakable norm, demonstrated different aesthetic properties and unlimited possibilities of art. And so every time there was a moving interpretation of the very phenomenon of art. Absolutization of any normative and "non-normative" theoretic manifestoes of art was broken by new waves of the artistically creative element. Ideas about the "death of art" or the declaration on the immortality of other stylistic forms were refuted by the productivity of new artistic stages. All this is convinced that any definitions of art must grow on the basis of a careful analysis of historical material, they can not "descend" as abstract constructs.

The language of art will always develop in the search for artistic equivalents of significant spiritual searches and experiences of man, as well as in an attempt to link the "subjectivity" of a person entangled in the mental networks of history with the higher spiritual Absolute. The process of creative search and evolution of language in our world is inexhaustible, because continuously our spirit always seeks in the unknown what is missing in the known. Art will always be a detonator of a new sense of life, a harbinger of important internal states that a person lives by, steps of approaching the sensation of Truth.

\section{REFERENCES}

[1] For more details, see: GlebPospelov, Jack of Diamonds, Moscow, Pinakothek, 2008, p. 288.

[2] Johann Eckermann. Conversations with Goethe in the last years of his life, Moscow, Publishing house "Fiction", 1986, pp. 411-412.

[3] Johann Joachim Winckelmann. Small works. Saint Petersburg. Palmyr, 2018, pp. 287-290.

[4] Sergey Stupin. The phenomenon of open form in the art of the twentieth century, Moscow, Indrick, 2012, p.312.

[5] Sergey Daniel. Networks for Proteus. The problems of interpretation of form in the visual arts. St. Petersburg, 2002, p. 57. 